\title{
SIMULATION OPTIMIZATION FOR THE INVENTORY MANAGEMENT OF HEALTHCARE SUPPLIES
}

\author{
Buschiazzo, M.*; Mula, J. ${ }^{* *} \&$ Campuzano-Bolarin, F. ${ }^{* * *}$ \\ * Universitat Politècnica de València, Research Centre on Production Management and Engineering \\ (CIGIP), Camí de Vera s/n, 46022 Valencia, Spain \\ ${ }^{* *}$ Universitat Politècnica de València, Research Centre on Production Management and Engineering \\ (CIGIP), Plaza Ferrándiz y Carbonell, 2, 03801, Alcoy, Alicante, Spain \\ Department of Business Economics, Universidad Politécnica de Cartagena, Spain \\ E-Mail: martbuschiazzo@gmail.com,fmula@cigip.upv.es, francisco.campuzano@upct.es
}

\begin{abstract}
This article covers the inventory management of healthcare supplies problem. Based on the mathematical programming model set out by [1], a causal model and a flow chart were developed to outline the simulation model, which was to be later applied to a highly specialized medical institution that performs high-risk heart surgery, such as catheterizations and angioplasties. With this simulation model, a purchases plan with 21 healthcare supplies was obtained that contemplates all the problem's restrictions: purchasing policy (safety stock, available budget); the warehouse's physical reality (warehouse capacity); characteristics of supplies (useful life, service level); and suppliers (price, capacity and size of lots or rounding value). Different indicators were also considered, such as service levels, costs of purchases, stockouts costs and inventory maintenance costs. The results obtained with the simulation model came very close to the mathematical programming results, but the computing times were considerably shorter.

(Received in March 2020, accepted in May 2020. This paper was with the authors 2 weeks for 1 revision.)
\end{abstract}

Key Words: Simulation Optimization, Inventory Management, Supply Chain Management, Healthcare Logistics, System Dynamics

\section{INTRODUCTION}

Given the high service level required to cover the critical lack of supplies in health care, many institutions manage a high inventory level [2]. Nonetheless, this does not often prove a suitable solution in all cases because supplies can expire and their administration to patients can pose a potential hazard [3]. According to [4], another relevant healthcare supplies management factor in a health institution is its high cost, which is especially due to its characteristics, controls and storage requirements. Inventory management in this context is a complex problem in which the importance of service level, and the characteristics of supplies, like high costs and expiry, stands out [5]. This article covers the inventory management problem of a highly specialized medical institution that performs high-risk heart surgery, such as catheterizations and angioplasties. Institutions of this kind have to highly concentrate human resources and materials for few patients with a critical life status who require specific procedures.

This paper addresses the inventory management for supplies required in high-risk heart surgeries and the potential impact to patients from a simulation model, which can reflect a suitable degree of realism and accuracy in describing the system and is capable of robustly and efficiently providing scenarios or what-if and sensitivity analyses [6-9]. Based on the mixed integer linear programming (MILP) model proposed by [1], a new simulation model was developed based on system dynamics for the inventory management of a highly specialized medical institution in order to provide a better understanding and evaluation of the problem under study. The aim was to draw up a purchases plan for all the supplies employed during high-risk heart surgery procedures at a minimum cost met the budget, service level, 
storage space limitations, and other restrictions associated with healthcare supplies and suppliers, such as expiry and delivery lot size. Another aim was to compare the simulation results with those obtained with the mathematical programming model by [1] to assess the pros and cons of the different approaches herein considered.

The main contribution of this paper is that it provides a new application of optimization simulation modelling based on system dynamics for inventory management in healthcare supplies. Generally speaking, the combination of optimization and simulation modelling based on system dynamics can considerably improve the decision-making processes in terms of obtaining, understanding and evaluating optimal solutions. More specifically, the proposed model can be considered a useful tool for improving performance in a healthcare supply chain as regards service levels, safety stocks, warehouse capacities, and their corresponding total costs. Other supply chain simulation models can be found in [10-14].

The rest of the article is as follows: Section 2 is a literature review on the theme; Section 3 considers the case study; Section 4 describes the simulation model with a causal diagram and a flow chart; Section 5 analyses the results from the different simulated scenarios and compares them with the mathematical programming model results; Section 6 offers the conclusions and possible future research lines.

\section{LITERATURE REVIEW}

Supply chain (SC) simulation helps explain how some controllable or uncontrollable factors affect SC performance. This allows improvements to be developed and validated, different alternatives to be reproduced and validated without affecting the real world, benefits to be quantified, and all or part of the complex system to be understood [15]. System dynamics [16] is based on industrial dynamics, as proposed by Forrester [17]. Größler et al. [18] demonstrate the usefulness of system dynamics as a structural theory and its models are taken as a content theory of operations management. In this way, content theories are defined as those containing hypotheses about a system's elements, while structural theories make statements about the causal relations between a system's elements and how they can be configured. Furthermore, system dynamics can be used to manage operations to explain, analyse and understand certain phenomena which, despite their existence being known, are not adequately considered, such as backlogs, feedback cycles and accumulation processes.

Jahangirian et al. [19] presented a literature review to provide the role that simulation techniques play in manufacturing and businesses. One result indicated that although the most popular technique was discrete event simulation, it implies less commitment by those involved than other techniques like system dynamics or business games. This might have something to do with the long usage time involved, whereas system dynamics appears more appealing given the ease with which standard conceptual modelling techniques are used that enrich brainstorming. This review also stressed that simulation techniques are extremely useful for other areas like SC management, strategy and knowledge management, among others, and also for classic applications like programming and process engineering. Finally, it confirmed that the simulation literature is very wide-ranging with both techniques and applications, and it unveiled a trend toward empirical studies instead of methodological studies, which is an indication of the discipline's maturity. Discrete event simulation and system dynamics are two widespread modelling approaches used to support decision making in SCs' logistics and management [20,21]. The literature review indicated that there were no differences in the modelling approach to be used when making (strategic or tactic/operational) decisions. Both simulation approaches have been used for SC and logistics problems to model most of the contemplated problems, albeit to different extents. Inventory management is one of the main SC management problems. 
Nowadays in some developing countries, working to control diseases is negatively influenced by SC problems. Lack of supplies of certain medicines can interrupt treatment, change diets, enhance resistance to their effectiveness and increase patients' death rates (Bam et al. [22]). Asamoah et al. [23] analysed a pharmaceutical SC to find deficiencies in the use of information technologies, which brought about backlogs and hindered the system. The main consequence was interrupted supplies and more deliveries were delayed. Onar et al. [24] sustain that making improvements to inventory management is one of the main areas to pay attention to in health care, where priority challenges include uncertainty in demand and limited human resources. Unclear demand and inventory can have serious consequences for both patient care and a hospital's economy. When medicines are lacking, emergency deliveries come into play at a higher cost, and this situation can also interrupt a patient's recovery process $[25,26]$. In addition, the healthcare industry affects economic development and society's well-being [26]. In this context, one of the SC's characteristics in the health sector is the dominant position occupied by the world's manufacturers of healthcare supplies. Shou [27] identified the main SC healthcare management problems: performance, cutting costs, inventory management, the bullwhip effect, quality, security and innovation. It was estimated that the costs of purchasing healthcare supplies represent $25 \%$ of a hospital's total costs, which can lower with improved SC efficiency. Moreover, one of the tools employed to analyse the interaction between organizations was system dynamics because it adapts to this type of highly complex SC. Other employed research methods and tools included case studies, surveys and meta-analyses. According to Onar et al. [24], over the last two decades, more importance has been attached to healthcare management in the literature. These authors classified problems and their solution techniques to identify the general healthcare management framework. The most widely used technique was simulation, whose objective in this context was to reproduce real-world systems over time based on repeated testing. Simulation was often used for epidemiological, molecular, pharmacological and disease modelling, and also as training programs to address security and quality, to develop evaluation standards for competences and education, and for virtual reality. Although considerable research about operations management in the pharmaceutical sector exists, very few research works have applied a system dynamics approach [28]. Onar et al. [24] maintain that it allows complex health, SC and disease progression problems to be modelled. Among healthcare SC problems, the work by [29] stands out, which sequentially presented three service levels without inventories and analysed the bullwhip effect and its services-related costs. Kochan et al. [25] used system dynamics to analyse conventional hospital SC performance and another SC that shared cloud-based information. This study's findings showed that exchanging information in the cloud increased the visibility of the inventory and demand in these SCs which, in turn, reduced the variation and averages of the inventory and delivery times, and improved customer service and forecasts at all levels. The inventory level of traditional SCs was considerably variable, particularly upstream of the manufacturer's level, which was caused by the bullwhip effect. Some of the proposed model's main considerations are: pending orders which could not be served during the same period, not taking into account the supplier's capacity restrictions, and both demand and lead time following a normal distribution. Bam et al. [22] quantitatively assessed the effectiveness of different SC policies scenarios to reduce scarcity and the costs of managing a given medicine in terms of reliability, capacity to respond and speed by following the reference SCOR (supply chain operation reference) framework. Tsolakis and Singh [28] developed a simulation model based on system dynamics to study the inventory management policies of "green" chemists employing renewable chemical raw materials. Wang et al. [30] presented an alternative inventory management model for an SC in a hospital, which was implemented using the system dynamics approach and based on Goldratt's Theory of constraints. Behzad et 
al. [31] also used system dynamics to model a hospital in-house services SC to calculate mistaken deliveries of medicines to patients.

It can be concluded that SCs in the healthcare sector is a relevant topic given its complexity and importance in the patient service level. However, despite different authors stating that the system dynamics approach is apt for modelling this SC type, very few articles conducted in the healthcare domain have been published to date. For all these reasons, it can be concluded that generating works that experiment with system dynamics is a need to model SCs in the healthcare sector in real case studies where it is possible to benefit from the positive aspects of this simulation methodology.

\section{PROBLEM DESCRIPTION}

The case study is based on a highly specialized medical institute (HSMI) of cardiology. Highly specialized medicine can be defined as that which requires a very high concentration of human and material resources for few patients. Life or functional prognosis is at stake, thus welfare excellence is sought. At the HSMI, and based on an annual budget, purchases are ordered on a 3-monthly basis for the following period and are placed with a set of suppliers whose "ranking" or priority follows the lower cost unit criterion. This order must be respected, and the next supplier can be selected if, and only if, the previous supplier's capacity is exhausted. Supplies can be served by either a single supplier or up to four suppliers, depending on the supply and each supplier's capacity. In turn, the suppliers establish a purchasing lot, also known as the "rounding value", derived from the units contained in a box. If supplies are lacking at the time of surgery, an emergency supply is obtained directly from the supplier or a substitute supply is employed. If this option is not possible, the patient is sent to another HSMI, which means the income that the hospital receives for surgery is lost and patient transfer costs are incurred, and it also poses more risks for the patient's health.

The problem of managing specialized medicine inventories consists in determining for each period how must of each supply to order and from which supplier to meet demand by minimizing costs. According to each supply's critical status, supplies are classified as vital, essential or desirable (VED). Each category has its defined service level, along with costs to use the safety stock as urgent purchases are made to replace it, which are not included in the budgeted expenditure. If the safety stock is used, it is considered an inventory stockout. Given the nature of this problem, no possible backlog exists. The annual budget cannot be accumulated and must be distributed into four 3-monthly periods during which purchases are made and the inventory cost is included in accountancy, which is stored in a limited space. Arrival of patients and the supplies used for each surgical procedure are considered known, but the safety stock contemplates possible variations in a real situation. As these supplies expire, a rule is set for FEFO (first expired, first out) use. The supplier sets a lot size or rounded quantity and a maximum supply capacity for each supply, which are instantly served. The model establishes two auxiliary periods: the first to set the baseline values, and the second to assign a usage period to the supplies not purchased so they can be used in the analysed horizon.

\section{SIMULATION MODEL}

It is worth stressing the differences with the mathematical programming model [1] to later compare the obtained results. A budget is considered for the whole planning horizon, and not on an annual basis. To simulate the supply's expiry constraint, maximum demand was calculated until this period and was multiplied by its useful life. This limits the purchases to 
the maximum amount that could be used before expiring. Stockout costs derive from the demand that cannot be served and that which is served as part of the safety stock. Although all supplies are simulated, only one supplier is considered. This is due to the pre-set priority order, which must be followed according to the list of suppliers, and it is only possible to move on to the next supplier if the previous supplier's capacity is exceeded. Hence this can be considered a trivial constraint and such simplification in the model only affects dividing the total purchase volume of each period according to the list of suppliers. We now move on to identify the elements making up the flow chart, divided into type of variable, e.g. level, flow or auxiliary, where index $i$ denotes supply. Table I provides the employed notation, while the next sections set out the equations.

Table I: Nomenclature for the flow chart.

\begin{tabular}{|c|c|}
\hline \multicolumn{2}{|c|}{ Level variables } \\
\hline IC & Accumulated cost incurred by inventory maintenance \\
\hline$I W_{i}$ & Inventory of supply $i$ \\
\hline$O C$ & Accumulated cost of purchases made \\
\hline$S L$ & Accumulated service level \\
\hline SOC & Accumulated cost incurred by stockout \\
\hline \multicolumn{2}{|c|}{ Flow variables } \\
\hline$D S_{i}$ & Served demand of supply $i$ \\
\hline$F O_{i}$ & End purchases of supply $i$ \\
\hline \multicolumn{2}{|c|}{ Auxiliary variables } \\
\hline$A B_{i}$ & Budget available for the purchases of supply $i$ \\
\hline$A T C$ & Total accumulated costs \\
\hline$B$ & Budget \\
\hline$B U$ & Budget used up to the period \\
\hline $\mathrm{CO}_{i}$ & Capacity used per supply $i$ \\
\hline$C R_{i}$ & Available warehouse capacity for the purchases of supply $i$ \\
\hline$D_{i}$ & Demand of supply $i$ \\
\hline$D N S_{i}$ & Unserved demand of supply $i$ \\
\hline$I C P$ & Inventory cost per period \\
\hline$I I_{i}$ & Initial inventory of supply $i$ \\
\hline$I V_{i}$ & Price of supply $i$ \\
\hline$I V O_{i}$ & Volume of supply $i$ \\
\hline$M D_{i}$ & Maximum quantity used to date of supply $i$ \\
\hline$M D D U L_{i}$ & Maximum quantity that can be used during the useful life of supply $i$ \\
\hline$M P_{i}$ & Minimum quantity that must be purchased to fulfil the safety stock policy of supply $i$ \\
\hline$M S L_{i}$ & Minimum service level of supply $i$ \\
\hline$P C_{i}$ & Supplier's replenishment capacity for supply $i$ \\
\hline$P C P$ & Purchases cost per period \\
\hline$P P R_{i}$ & Quantity to purchase of supply $i$ to fulfill the supplier's constraints \\
\hline$P P W C R_{i}$ & Purchases that can be paid without bearing in mind the capacity constraint of supply $i$ \\
\hline$P R V_{i}$ & Quantity to purchase of supply $i$ to fulfill the supplier's rounding value constraint \\
\hline$R S L$ & Real service level of the period \\
\hline$R S L I_{i}$ & Real service level of the period for supply $i$ \\
\hline$R V_{i}$ & The supplier's rounding value for supply $i$ \\
\hline$S O C P$ & Stockout cost per period \\
\hline$S S_{i}$ & Safety stock of supply $i$ \\
\hline$T C P$ & Total costs per period \\
\hline$U I C_{i}$ & Unit cost of the inventory of supply $i$ \\
\hline$F T$ & Final planning time \\
\hline$U L_{i}$ & Useful life of supply $i$ \\
\hline$U S O C_{i}$ & Unit cost of the stockout of supply $i$ \\
\hline$U S S_{i}$ & Safety stock used of supply $i$ \\
\hline$W C$ & Warehouse capacity \\
\hline
\end{tabular}

\section{Level variables}

$$
\begin{aligned}
& O C(t)=\int_{t_{0}}^{t}\left[\sum_{i} F O_{i}(t) * I V_{i}(t)\right] d t ; O C\left(t_{0}\right)=0 \\
& I C(t)=\int_{t_{0}}^{t}\left[\sum_{i} I W_{i}(t) * U I C_{i}(t)\right] d t ; I C\left(t_{0}\right)=0
\end{aligned}
$$




$$
\begin{gathered}
\operatorname{SOC}(t)=\int_{t_{0}}^{t}\left[\sum_{i} \operatorname{USOC}_{i}(t) * \operatorname{DNS}_{i}(t)+\operatorname{USS}_{i}(t) * \operatorname{USOC}_{i}(t)\right] d t ; \operatorname{SOC}\left(t_{0}\right)=0 \\
I W_{i}(t)=\int_{t_{0}}^{t}\left[\mathrm{FO}_{i}(t)-D S_{i}(t)\right] d t ; I W_{i}\left(t_{0}\right)=I I_{i} ; \forall i \\
S L(t)=\int_{t_{0}}^{t}\left[\frac{R S L(t)}{T F}\right] d t ; S L\left(t_{0}\right)=0
\end{gathered}
$$

Flow variables

$$
\begin{gathered}
F O_{i}(t)=\operatorname{Min}\left(\min \left(P P W C R_{i}(t), C R_{i}(t)\right), M D D U L_{i}(t) ;\right. \\
D S_{i}(t)=\left\{\begin{array}{c}
D_{i}(t)<I W_{i}(t)+F O_{i}(t), D_{i}(t) \\
\left\{\begin{array}{c}
D_{i}(t) * \frac{M S L_{i}}{100}<I W_{i}(t)+F O_{i}(t), D_{i}(t) * M S L_{i} \\
\text { if not, } 0
\end{array} ; \forall i\right.
\end{array}\right.
\end{gathered}
$$

\section{Auxiliary variables}

$$
\begin{aligned}
& M P_{i}(t)=\left\{\begin{array}{c}
\text { if } I W_{i}(t)<\left(S S_{i}+D_{i}(t)\right), D_{i}(t)+S S_{i}-I W_{i}(t), \\
\text { if not, } 0
\end{array} \forall i\right. \\
& \operatorname{PRV}_{i}(t)=\left\{\begin{array}{c}
\operatorname{if} \mathrm{MP}_{i}(t)=0,0 \\
\text { if not, } \operatorname{INTEGER}\left(\frac{\mathrm{MP}_{i}(t)-0.1}{R V_{i}}+1\right) * R V_{i}
\end{array} ; \forall i\right. \\
& P P R_{i}(t)=\left\{\begin{array}{c}
\text { if } P R V_{i}(t)>P C_{i}, P C_{i}, \\
\text { if not, } P R V_{i}(t)
\end{array} ; \forall i\right. \\
& \operatorname{PPWCR}_{i}(t)=\left\{\begin{array}{c}
\text { if } P P R_{i}(t) * \mathrm{IV}_{i}<A B_{i}(t), \text { then } P P R_{i}(t) \\
\text { if not, } 0
\end{array} ; \forall i\right. \\
& C O_{i}(t)=I W_{i}(t) * I V O_{i} ; \forall i \\
& M D D U L_{i}(t)=\operatorname{INTEGER}\left(\frac{M D_{i}(t) * U L_{i}-0.1}{R V_{i}}+1\right) * R V_{i} ; \forall i \\
& P C P(t)=\sum_{i} F O_{i}(t) * I V_{i} \\
& \operatorname{ICP}(t)=\left\{\begin{array}{c}
\text { if } t=0,0 \\
\text { if not, } \sum_{i} I W_{i}(t) * U I C_{i}
\end{array}\right. \\
& \operatorname{SOCP}(t)=\sum_{i}\left(U_{S O C} * D N S_{i}(t)+U S S_{i}(t) * U S O C\right) \\
& A T C=O C(t)+\operatorname{IC}(t)+\operatorname{SOC}(t) \\
& T C P(t)=P C P(t)+I C P(t)+\operatorname{SOCP}(t) \\
& M D_{i}(t)=\operatorname{MAX}\left(\text { SMOOTHI }\left(M D_{i}, 1, D_{i}(1)\right), D_{i}(t)\right) ; \forall i \\
& U S S_{i}(t)=\left\{\begin{array}{c}
\text { if } I W_{i}(t)<S S_{i}, S S_{i}-I W_{i}(t) \\
\text { if not, } 0
\end{array} ; \forall i\right. \\
& R S L(t)=X I D Z\left(\sum_{i} D S_{i}(t), \sum_{i} D_{i}(t), 1\right) \\
& R S L I_{i}(t)=X I D Z\left(D S_{i}(t), D_{i}(t), 1\right) ; \forall i \\
& A B_{i}(t)=\operatorname{MAX}\left(B-B U(t)-(F T-t) * \sum_{i}\left(S S_{i} * U I C_{i}, 0\right) ; \forall i\right. \\
& B U(t)=O C(t)+I C(t) \\
& D N S_{i}(t)=D_{i}(t)-D S_{i}(t) ; \forall i \\
& C R_{i}(t)=\frac{W C-\sum_{i} C O_{i}(t)}{I V O_{i}} ; \forall i
\end{aligned}
$$

In order to validate the proposed model, the results obtained with the MILP model were compared using the same input data. The MILP model was coded in AMPL and was solved with version 12.6.3.0 of the CPLEX software in a PC Intel Core i7 5960X 3.50GHz, with 16 CPUs, 64 GB of RAM (DDR4-2133) and in the CentOS 7 operating system. The optimum solution was found after 7,460 seconds. As mentioned in the simplifications section, the budget in the simulation model was considered for the complete planning horizon and not 
annually. This is comparable to one of the sensitivity scenarios considered by [1], in which the annual budget was increased by $25 \%$ to relax the problem, which means that the budget is no longer a limiting variable. In this case, the optimum solution came after 550 seconds and it was used to make the comparison. The running time of the simulation model run with Vensim ${ }^{\circledR}$ was less than 1 second and was, thus, practically null. It was run on an Intel Core processor i5 $4210 \mathrm{U} 2.4 \mathrm{GHz}$, with $8 \mathrm{~GB}$ of RAM and in a 64-bit operating system. Table II compares the costs of the solutions. It shows how the total difference was almost negligible $(0.02 \%)$, which was given by a lower inventory cost $(1.2 \%)$, but with much higher stockout costs $(369 \%)$.

Table II: Comparing costs.

\begin{tabular}{|l|c|c|}
\hline \multicolumn{1}{|c|}{ Concept } & MILP model $(€)$ & Simulation model $(€)$ \\
\hline Purchases cost & $25,465.179$ & $25,468.599$ \\
\hline Stockout cost & 4,158 & 19,494 \\
\hline Inventory cost & 993,830 & 981,544 \\
\hline Total & $26,463.167$ & $26,469.637$ \\
\hline
\end{tabular}

Table III shows the purchases, the employed safety stock (which is the equivalent to the quantity of stockouts in the MILP model) and the inventory for each period according to the approaches followed in the employed modelling. As expected, and in accordance with the increase in costs, there were more stockouts during periods 4 and 5 . This was due to the purchases of two supplies being limited by the supplier's capacity. In the MILP model, when it was not necessary to purchase the maximum capacity during certain periods, this quantity was purchased to avoid using the safety stock during later periods. In the simulation model, only the minimum amount required for this period was purchased.

Table III: Comparison in units according to the followed modelling approach.

\begin{tabular}{|c|c|c|c|c|c|c|c|c|c|c|}
\hline \multirow{4}{*}{ 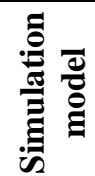 } & Period & 1 & 2 & 3 & 4 & 5 & 6 & 7 & 8 & Total \\
\hline & Purchases $(F O)$ & 2,838 & 3,145 & 3,663 & 3,522 & 3,088 & 3,653 & 3,309 & 3,804 & 27,022 \\
\hline & Used safety stock (USS) & - & - & - & 18 & 20 & - & - & - & 38 \\
\hline & Inventory $(I W)$ & 1,283 & 1,328 & 1,303 & 1,268 & 1,263 & 1,318 & 1,288 & 1,308 & 10,359 \\
\hline \multirow{3}{*}{ 胥 } & Purchases $(F O)$ & 2,867 & 3,196 & 3,643 & 4,000 & 2,585 & 3,642 & 3,309 & 3,796 & 27,038 \\
\hline & Used safety stock (USS) & - & - & 9 & 1 & - & - & - & 1 & 11 \\
\hline & Inventory $(I W)$ & 1,357 & 1,358 & 1,312 & 1,298 & 1,363 & 1,322 & 1,342 & 1,310 & 10,662 \\
\hline
\end{tabular}

\section{EVALUATION OF RESULTS}

The main variables used to analyse the results were purchases, inventory and served demand. Overall, fewer purchases had to be made to fulfil the safety stock policy than those made given the supplier's restrictions, and the budget and available warehouse space also lowered. However, this was not the case during all the periods, as seen in Table IV. There were basically two reasons for this: on the one hand, the supplier's capacity constraint, which limits purchases, which means having to purchase less than what is needed and to use part of the safety stock; on the other hand, the supplier's rounding value involves purchasing the next multiple, and thus incurring "excess."

Table IV: Final orders with no constraints per period.

\begin{tabular}{|l|cccccccc|c|}
\hline \multicolumn{1}{|c}{ Time period } & $\mathbf{1}$ & $\mathbf{2}$ & $\mathbf{3}$ & $\mathbf{4}$ & $\mathbf{5}$ & $\mathbf{6}$ & $\mathbf{7}$ & $\mathbf{8}$ & Total \\
\hline $\begin{array}{l}\text { Purchases according to } \\
\text { policy (no restrictions) - } M P\end{array}$ & 2,793 & 3,125 & 3,678 & 3,542 & 3,053 & 3,648 & 3,284 & 3,804 & 26,927 \\
\hline Final Orders - FO & 2,838 & 3,145 & 3,663 & 3,522 & 3,088 & 3,653 & 3,309 & 3,804 & 27,022 \\
\hline Difference & 45 & 20 & -15 & -20 & 35 & 5 & 25 & - & 95 \\
\hline
\end{tabular}


This purchases plan affects the inventory level by rendering it necessary to use part of the safety stock during periods 4 and 5. As a result, $100 \%$ demand is served, with a $100 \%$ service level during all the time periods. For the planning horizon, costs rise to $€ 26,469.637$, where purchases is the biggest component in terms of cost (96\%), inventory $€ 981,544(3,7 \%)$ and safety stock uses $€ 19,494(0,1 \%)$.

The sensitivity analyses were carried out with the "Monte Carlo simulation" tool of Vensim ${ }^{\circledR}$. The parameters to analyse were safety stock $\left(S S_{i}\right)$ and capacity $\left(P C_{i}\right)$. For them, a maximum and a minimum value were selected (-20 to $20 \%$ for $S S_{i}$ and -50 to $50 \%$ for $P C_{i}$ ), respectively), and uniform random distribution was chosen to generate the values to be used while running 200 simulations. There are several reasons why the suppliers' capacity may be affected. Some have to do with technological changes, negotiations, changes made to other customers' orders, disruptions in the SC due to natural disasters or other events. When analysing the results obtained with variation in capacity, the impact on total costs was much stronger for the simulations with a lower capacity than the real capacity. This was due to the high cost involved in not serving or in using the safety stock to perform this, as observed when comparing the baseline (in blue) in Fig. 1, where the safety stock can be seen. The yellow strip represents $50 \%$ of the results, green $75 \%$, blue $95 \%$ and grey $100 \%$.

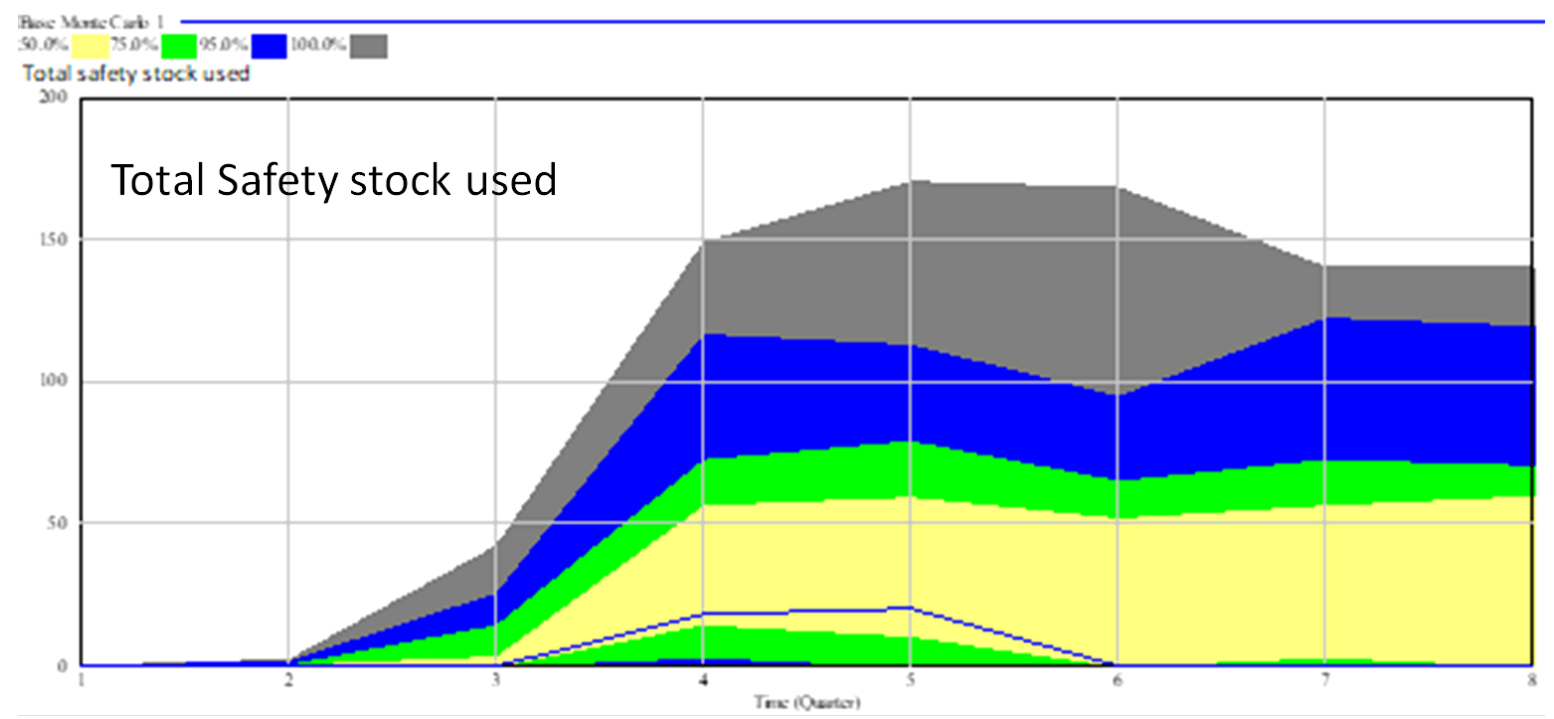

Figure 1: Safety stock in the sensitivity analysis with variation in the supplier's capacity.

Regarding variation in the parameter safety stock per supply, the immediate impact appeared on the inventory level. One noteworthy aspect was that demand was met in all the simulated scenarios, despite it sometimes being necessary to use part of the safety stock. This suggests that changes to this parameter, which depends on the HSMI's management, can offer economic improvements without them affecting the service level.

In both the MILP and simulation models, demand is assumed to be known. However, given the problem's characteristics where most of the patients resorted to HSMI when an emergency situation arose, it was impossible to accurately know the demand of supplies until they were actually required. Hence the interest in observing the model results when varying demand per supply. In order to consider demand to be a uniform normal probability distribution, a statistical analysis was carried out to determine the minimum, maximum, mean and standard deviation values. It is important to stress that for the performed Monte Carlo simulation, 400 simulations were run in this case, which is twice the number than in previous sections, and the baseline scenario it is the first case with random demand, i.e., not the same as the original problem. The sensitivity analyses revealed that the model was consistent without it performing strangely. 
With $\operatorname{Vensim}{ }^{\circledR}$, optimization can be used to validate the estimated parameters (calibration) or to select the best policy among several alternatives (optimized policy), where the latter corresponded to our case study. To do so, it is necessary to predefine what is understood by a good result (outcome measure) and which parameters could vary, and at what magnitudes, to obtain the "best result". Next the intention was to find the best safety stock configuration for the inventory management problem of specialized healthcare supplies using two optimization events: first, by taking the total costs as the only outcome measure (optimization 1); next, by also measuring the impact on the quantity of stockouts by attaching more importance to it (optimization 2). To suitably perform optimization, it is necessary to modify the model and create a random variable that represents real demand per supply. This means that the demand employed in the former model is only useful for forecasting; that is, purchase orders are placed without knowing what demand is exactly. Moreover, the "real demand per supply" is that which uses the inventory and measures the service level, and is modelled by a random variable with normal distribution according to the characteristics of real demand. Therefore, by using 2,214 simulations, the "optimum" safety stock is determined. Despite the total costs being $4.5 \%$ lower, part of demand is not met during four periods, which could pose serious problems for the patient's health. Therefore, a new optimization of both total costs and unserved demand was carried out by varying the safety stock. In this case, and after 2,251 simulations, a safety stock value was obtained that made the total costs "optimum" and all demand was served. The total costs were only $0.46 \%$ higher than in the previous scenario, which was an improvement on the baseline $4.1 \%$. Thus, total costs to serve complete demand in the baseline scenario were $€ 30,529.061$, for optimization 1 were $€ 29,146.164$ and for optimization $€ 29,280.011$. This proves the strength of the proposal to solve a static problem with results nearly to the optimal with minor computational times but also to solve a dynamic problem reaching desired results in this case in terms of service levels and total costs. Here, it is important to highlight the complementary usefulness of MILP and simulation models in order to provide a better understanding of a problem through scenarios simulation at minimum computational times. Finally, it is important to highlight that the proposed model can be easily extended to any number of healthcare supplies and time periods. More details on the flow chart, reference MILP model, input data and output data can be found in: https://cigip.webs.upv.es/docs/2020_IJSIMM_Buschiazzo_et_al_metadata.pdf

\section{CONCLUSIONS}

This paper has proposed a simulation model for the inventory management problem in a highly specialized medical institution, which is an interesting topic given its complexity and the importance attached to patients' service level. Based on the work by [1], a simulation model that included the main problem characteristics was created and validated. The obtained result is slightly lower than the optimization result (total costs rose by $0.02 \%$ ), but the execution involved a practically null solution time, as opposed to 550 seconds. The analysis of the results led to a purchases plan that met demand during all the periods. Then several sensitivity analyses were carried out by individually and simultaneously varying some parameters, like safety stock and capacity. Varying the total costs revealed the importance of suitably managing these parameters. Another problem model was used which considered random demand to analyse its impact on the results which, along with the sensitivity analyses herein performed, proved a very useful tool. Managerial implications from this analysis are related to, for example, obtaining the quantity to be purchased for each supply that is needed to cover random demand at the desired confidence interval. This allows the possible requirements to cover a given random demand to be anticipated. For instance, increase the budget if analysing costs, adjust capacity when analysing the inventory level, negotiate 
changes with suppliers or "anticipate purchases" whenever necessary. It is also possible to analyse the risk level at which the service level is not met. There is only one scenario in which demand is not met. Although probability is very low (1 case in 400 simulations), it is worth studying the case and seeking alternatives to avoid this happening by bearing in mind the critical lack status of the healthcare supply in question because it could involve a patient dying.

The main scientific original contribution to the simulation modelling field is oriented to provide a reproducible model able to anticipate possible requirements in the SC configuration and to analyse the expected service level according to the desired confidence interval. Along the same lines, the safety stock per supply was optimized to minimize the total costs. As this solution did not meet demand during certain periods, further optimization was carried out to weight the service level by attaching more importance to it. In this case, another combination of safety stock values was obtained which met $100 \%$ demand and involved increase in costs of only $0.46 \%$. Other important contributions of the proposal herein presented are that it helped to explain and understand the SC and, in turn, involves a shorter running time to obtain a purchases plan compared to the MILP model. Thus it was possible to easily manage limited resources, such as money or warehouse capacity, and to make future service level estimations using confidence intervals. This allowed savings to be quantified when changes were made to some parameters that depend on the organization, e.g. safety stock, or involved previously negotiating with suppliers, e.g., rounding value. The possibility of experimenting with different strategies or alternatives and observing not only the economic impact, but also the direct impact on the service level, is stressed because if this aspect is tested in the real world, it could seriously affect patients' health. Finally, it is important to highlight the contribution of this paper on the case we have modelled and the potential impact on healthcare services providers, patients and society.

Several possible future research lines emerged while this work was underway. For example, the model could include other characteristics of SCs with randomness or uncertainty, such as variable lead times and suppliers' service level. This proposal could be applied to other similar SC by including more participants and bearing in mind other characteristics, such as quality, trust and lead times. Optimization could be sought by varying other parameters that the SC controls to improve its overall performance. To this end, other performance indicators would have to be included in the model to allow SC management. Finally, it would be interesting to conduct other works about healthcare SCs that use the advantages of system dynamics and which prioritize the involved patients by contributing to people's health.

\section{ACKNOWLEDGEMENT}

This work was supported by the Spanish Ministry of Science, Innovation and Universities project entitled 'Optimisation of zero-defects production technologies enabling supply chains 4.0 (CADS4.0)' (RTI2018-101344-B-I00) and the Operational Program of the European Regional Development Fund (ERDF) of the Valencian Community 2014-2020 IDIFEDER/2018/025.

\section{REFERENCES}

[1] Piñeyro, P.; Artecona, G.; Bonilla, S.; Buschiazzo, M. (2018). Gestión de inventario para una institución de medicina altamente especializada de Uruguay, Proceedings of the $19^{\text {th }}$ LatinIberoamerican Conference on Operations Research, 300-307

[2] Uthayakumar, R.; Priyan, S. (2013). Operations research for health care pharmaceutical supply chain and inventory management strategies: optimization for a pharmaceutical company and a hospital, Operations Research for Health Care, Vol. 2, No. 3, 52-64, doi: $10.1016 /$ j.orhc.2013.08.001 
[3] Saedi, S.; Kundakcioglu, O. E.; Henry, A. C. (2016). Mitigating the impact of drug shortages for a healthcare facility: an inventory management approach, European Journal of Operational Research, Vol. 251, No. 1, 107-123, doi:10.1016/j.ejor.2015.11.017

[4] Kelle, P.; Woosley, J.; Schneider, H. (2012). Pharmaceutical supply chain specifics and inventory solutions for a hospital case, Operations Research for Health Care, Vol. 1, No. 2-3, 54-63, doi:10.1016/j.orhc.2012.07.001

[5] Bijvank, M.; Vis, I. F. A. (2012). Inventory control for point-of-use locations in hospitals, Journal of the Operational Research Society, Vol. 63, No. 4, 497-510, doi:10.1057/jors.2011.52

[6] Georgiadis, P.; Michaloudis, C. (2012). Real-time production planning and control system for job-shop manufacturing: a system dynamics analysis, European Journal of Operational Research, Vol. 216, No. 1, 94-104, doi:10.1016/j.ejor.2011.07.022

[7] Georgiadis, P.; Politou, A. (2013). Dynamic drum-buffer-rope approach for production planning and control in capacitated flow-shop manufacturing systems, Computers \& Industrial Engineering, Vol. 65, No. 4, 689-703, doi:10.1016/j.cie.2013.04.013

[8] Mula, J.; Campuzano-Bolarin, F.; Diaz-Madroñero, F.; Carpio, K. M. (2013). A system dynamics model for the supply chain procurement transport problem: comparing spreadsheets, fuzzy programming and simulation approaches, International Journal of Production Research, Vol. 51, No. 13, 4087-4104, doi:10.1080/00207543.2013.774487

[9] Esteso, A.; Mula, J.; Campuzano-Bolarín, F.; Alemany, M. M. E.; Ortiz, A. (2019). Simulation to reallocate supply to committed orders under shortage, International Journal of Production Research, Vol. 57, No. 5, 1552-1570, doi:10.1080/00207543.2018.1493239

[10] Diez, M.; Mula, J.; Campuzano-Bolarin, F. (2014). Improvement of a distribution network of a direct sale cosmetics supply chain, International Journal of Simulation Modelling, Vol. 13, No. 1, 16-29, doi:10.2507/IJSIMM13(1)2.245

[11] Moreno, J. R.; Mula, J.; Campuzano-Bolarin, F. (2015). Increasing the equity of a flower supply chain by improving order management and supplier selection, International Journal of Simulation Modelling, Vol. 14, No. 2, 201-214, doi:10.2507/IJSIMM14(2)2.284

[12] Pacheco, E. de O.; Cannella, S.; Lüders, R.; Barbosa-Povoa, A. P. (2017). Order-up-to-level policy update procedure for a supply chain subject to market demand uncertainty, Computers \& Industrial Engineering, Vol. 113, 347-355, doi:10.1016/J.CIE.2017.09.015

[13] Moon, S.; Ji, W.; Moon, H.; Kim, D. (2018). A simulation of order resonance phenomenon in a supply chain triggered by reinforcing loop, International Journal of Simulation Modelling, Vol. 17, No. 2, 231-244, doi:10.2507/IJSIMM17(2)421

[14] Campuzano-Bolarín, F.; Mula, J.; Díaz-Madroñero, M.; Legaz-Aparicio, A. G. (2020). A rolling horizon simulation approach for managing demand with lead time variability, International Journal of Production Research, in press, 21 pages, doi:10.1080/00207543.2019.1634849

[15] Campuzano, F.; Mula, J. (2011). Supply Chain Simulation: A System Dynamics Approach for Improving Performance, Springer-Verlag, London, doi:10.1007/978-0-85729-719-8

[16] Sterman, J. D. (2000). Business Dynamics: Systems Thinking and Modeling for a Complex World, McGraw-Hill, Boston

[17] Forrester, J. W. (1961). Industrial Dynamics, The MIT Press, Cambridge

[18] Größler, A.; Thun, J.-H.; Milling, P. M. (2009). System dynamics as a structural theory in operations management, Production and Operations Management, Vol. 17, No. 3, 373-384, doi: 10.3401/poms.1080.0023

[19] Jahangirian, M.; Eldabi, T.; Naseer, A.; Stergioulas, L. K.; Young, T. (2010). Simulation in manufacturing and business: a review, European Journal of Operational Research, Vol. 203, No. 1, 1-13, doi:10.1016/j.ejor.2009.06.004

[20] Tako, A. A.; Robinson, S. (2012). The application of discrete event simulation and system dynamics in the logistics and supply chain context, Decision Support Systems, Vol. 52, No. 4, 802-815, doi:10.1016/j.dss.2011.11.015

[21] Vieira, A. A. C.; Dias, L. M. S.; Santos, M. Y.; Pereira, G. A. B.; Oliveira, J. A. (2018). Setting an industry 4.0 research and development agenda for simulation - a literature review, International Journal of Simulation Modelling, Vol. 17, No. 3, 377-390, doi:10.2507/IJSIMM17(3)429 
[22] Bam, L.; Mclaren, Z. M.; Coetzee, E.; von Leipzig, K. H. (2017). Reducing stock-outs of essential tuberculosis medicines: a system dynamics modelling approach to supply chain management, Health Policy and Planning, Vol. 32, No. 8, 1127-1134, doi:10.1093/ heapol/czx057

[23] Asamoah, D.; Abor, P.; Opare, M. (2011). An examination of pharmaceutical supply chain for artemisinin-based combination therapies in Ghana, Management Research Review, Vol. 34, No. 7, 790-809, doi:10.1108/01409171111146689

[24] Cevik Onar, S.; Oztaysi, B.; Kahraman, C. (2018). A comprehensive survey on healthcare management, Kahraman, C.; Topcu, Y. (Eds.), Operations Research Applications in Health Care Management, International Series in Operations Research \& Management Science, Vol. 262, 23 44, doi:10.1007/978-3-319-65455-3 2

[25] Kochan, C. G.; Nowicki, D. R.; Sauser, B.; Randall, W. S. (2018). Impact of cloud-based information sharing on hospital supply chain performance: a system dynamics framework, International Journal of Production Economics, Vol. 195, 168-185, doi:10.1016/ j.ijpe.2017.10.008

[26] Fragapane, G. L.; Zhang, C.; Sgarbossa, F.; Strandhagen, J. O. (2019). An agent-based simulation approach to model hospital logistics, International Journal of Simulation Modelling, Vol. 18, No. 4, 654-665, doi:10.2507/IJSIMM18(4)497

[27] Shou, Y. (2013). Perspectives on supply chain management in the healthcare industry, Proceedings of the $2^{\text {nd }}$ International Conference on Science and Social Research, 630-633, doi:10.2991/icssr-13.2013.144

[28] Tsolakis, N.; Srai, J. S. (2017). Inventory planning and control in 'green' pharmacies supply chains - a system dynamics modelling perspective, Computer Aided Chemical Engineering, Vol. 40, 1285-1290, doi:10.1016/B978-0-444-63965-3.50216-6

[29] Samuel, C.; Gonapa, K.; Chaudhary, P. K.; Mishra, A. (2010). Supply chain dynamics in healthcare services, International Journal of Health Care Quality Assurance, Vol. 23, No. 7, 631-642, doi:10.1108/09526861011071562

[30] Wang, L.-C.; Cheng, C.-Y.; Tseng, Y.-T.; Liu, Y.-F. (2015). Demand-pull replenishment model for hospital inventory management: a dynamic buffer-adjustment approach, International Journal of Production Research, Vol. 53, No. 24,7533-7546, doi:10.1080/00207543.2015.1102353

[31] Behzad, B.; Moraga, R. J.; Chen, S.-J. (2011). Modelling healthcare internal service supply chains for the analysis of medication delivery errors and amplification effects, Journal of Industrial Engineering and Management, Vol. 4, No. 4, 554-576, doi:10.3926/jiem.201 